\section{BRAZIULIAN JOURNAL}

OF MEDICAL AND BIOLOGICAL RESHARCH

www.bjournal.com.br
ISSN 0100-879X

Volume 43 (01) 1-123 January 2010

BIOMEDICAL SCIENCES

AND

CLINICAL INVESTIGATION

Braz J Med Biol Res, J anuary 2010, Volume 43(1) 107-114

\title{
HFE gene mutations and iron status of Brazilian blood donors
}

P.C.J.L. Santos, R.D. Cançado, C.T. Terada, S. Rostelato, I. Gonzales, R.D.C. Hirata, M.H. Hirata, C.S. Chiattone and E.M. Guerra-Shinohara

The Brazilian Journal of Medical and Biological Research is partially financed by
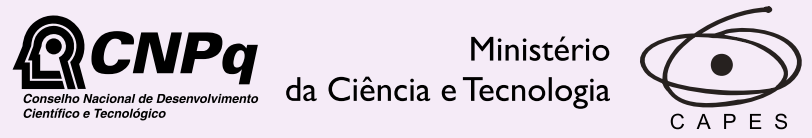

Ministério da Educação

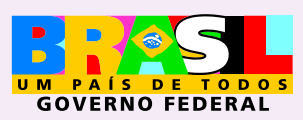

Institutional S ponsors 


\title{
HFE gene mutations and iron status of Brazilian blood donors
}

\author{
P.C.J.L. Santos ${ }^{1}$, R.D. Cançado ${ }^{2}$, C.T. Terada1 ${ }^{1}$, S. Rostelato1, I. Gonzales ${ }^{1}$, \\ R.D.C. Hirata1 ${ }^{1}$, M.H. Hirata ${ }^{1}$, C.S. Chiattone ${ }^{2}$ and E.M. Guerra-Shinohara ${ }^{1}$ \\ 1Departamento de Análises Clínicas e Toxicológicas, Faculdade de Ciências Farmacêuticas, \\ Universidade de São Paulo, São Paulo, SP, Brasil \\ ${ }^{2}$ Departamento de Hematologia/Oncologia, Faculdade de Medicina da Santa Casa de São Paulo, \\ São Paulo, SP, Brasil
}

\begin{abstract}
Mutations of the HFE and TFR2 genes have been associated with iron overload. HFE and TFR2 mutations were assessed in blood donors, and the relationship with iron status was evaluated. Subjects $(N=542)$ were recruited at the Hemocentro da Santa Casa de São Paulo, São Paulo, Brazil. Iron status was not influenced by HFE mutations in women and was independent of blood donation frequency. In contrast, men carrying the HFE 282CY genotype had lower total iron-binding capacity (TIBC) than HFE 282CC genotype carriers. Men who donated blood for the first time and were carriers of the HFE 282CY genotype had higher transferrin saturation values and lower TIBC concentrations than those with the homozygous wild genotype for the HFE C282Y mutation. Moreover, in this group of blood donors, carriers of HFE 63DD plus 63HD genotypes had higher serum ferritin values than those with the homozygous wild genotype for HFE H63D mutation. Multiple linear regression analysis showed that HFE $282 \mathrm{CY}$ leads to a $17.21 \%$ increase $(P=0.018)$ and a $83.65 \%$ decrease $(P=0.007)$ in transferrin saturation and TIBC, respectively. In addition, serum ferritin is influenced by age $(3.91 \%, \mathrm{P}=0.001)$ and the HFE 63HD plus DD genotype $(55.84 \%, P=0.021)$. In conclusion, the HFE $282 \mathrm{Y}$ and $65 \mathrm{C}$ alleles were rare, while the HFE 63D allele was frequent in Brazilian blood donors. The HFE C282Y and H63D mutations were associated with alterations in iron status in blood donors in a gender-dependent manner.
\end{abstract}

Key words: HFE; TFR2; Gene mutations; Blood donors; Iron status

\section{Introduction}

Iron is essential for the adequate functioning of metabolic and structural proteins in cells. Proteins, such as HFE, hemojuvelin, transferrin receptor 2 (TFR2), and ferroportin, and a peptide called hepcidin, regulate iron metabolism. Mutations in the genes of these proteins or peptide are associated with the etiology of iron overload (hereditary hemochromatosis, $\mathrm{HH}$ ), which is characterized by increased intestinal iron absorption and progressive accumulation of iron in the body (1).

The HFE protein forms a complex with $\beta_{2}$-microglobulin and this complex can interact with transferrin receptor 1 (TFR1), decreasing its affinity for transferring and consequently modulating iron absorption in enterocytes (2). TFR2 is expressed predominantly in the liver, is implicated in the uptake of iron by hepatocytes through a receptormediated endocytosis mechanism, and has a high degree of homology with TFR1 (3).

Several mutations in the HFE gene have been associated with $\mathrm{HH}$ in different populations (4). The HFE G845A (C282Y) mutation is frequent in a healthy population from Northern Europe (10\%) (1), but is rare or absent in African, Asian, South Pacific, and Aboriginal Australian populations (5). Higher frequencies of C282Y were found in individuals with $\mathrm{HH}$, decreasing from Northern to Southern Europe, with the highest percentage occurring in Brittany (96\%) (6) and the lowest in Italy (64\%) (7) and Greece (39\%) (8).

Two other HFE mutations (C187G and A193T) are characterized by substitutions of histidine to aspartic acid at position 63 (H63D) (9) and serine to cysteine at position 65 (S65C), respectively (10). The HFE 63D allele in the absence of the HFE 282Y allele was shown to be associated with a low risk for $\mathrm{HH}$. However, the HFE

Correspondence: E.M. Guerra-Shinohara, Departamento de Análises Clínicas e Toxicológicas, Faculdade de Ciências Farmacêuticas, USP, Av. Prof. Lineu Prestes, 580, 05508-900 São Paulo, SP, Brasil. Fax: +55-11-3813-2197. E-mail: emguerra@usp.br

Received July 1, 2009. Accepted December 4, 2009. Available online December 18, 2009. Published January 11, 2010. 
H63D mutation is inherited in heterozygosis with the HFE C282Y mutation, and the carrier has an elevated risk of developing $\mathrm{HH}$ compared to an individual with the HFE 282YY genotype $(7,11)$.

TFR2 gene mutations are less frequent than HFE mutations. The TFR2 Y250X mutation, detected in a Sicilian family (12), is a nonsense mutation characterized by impairment of TFR2 protein and, consequently, alterations in iron regulation. The Q690P mutation was detected in a Portuguese man and in two of his family members with the $\mathrm{HH}$ phenotype (13). These two mutations in TFR2 were demonstrated in $\mathrm{HH}$ patients, but their frequencies in healthy individuals are unknown.

A few studies have evaluated the frequency of the HFE C282Y mutation in Brazilian healthy individuals, but the effect of this mutation on iron status in Brazilian healthy blood donors is not known (14-16). In addition, the frequency of TFR2 mutations in the Brazilian healthy population is also not known. The objectives of this study were to determine the frequencies of functional mutations in the HFE and TFR2 genes, and to identify their relationship to iron status in blood donors.

\section{Material and Methods}

\section{Study population}

This study included 542 Brazilian healthy volunteers randomly selected among blood donors from Hemocentro da Santa Casa de São Paulo, SP, Brazil, in 2005. Two Ethics Committees (Santa Casa and Faculdade de Ciências Farmacêuticas) approved the study protocol, and written informed consent was obtained from all participants prior to entering the study.

Demographic data and the frequency of previous donations were obtained by a structured interview. Each person self-identified as White, Intermediate, Black, or Yellow according to the skin color categories defined by the Brazilian Census (17). The ethnic self-identification classification was compared with ancestry informative markers in a recent Brazilian study, which concluded that Brazilian individuals should be considered as a heterogeneous population $(18,19)$.

Blood donors were divided into three groups according to the frequencies of blood donations. The individuals who donated blood for the first time were classified as first-time donors. Individuals who had donated blood more than once in the last 12 months were classified as frequent donors. Last, individuals who donated blood any time prior to the last 12 months were classified as sporadic blood donors.

Only individuals with hematocrit values higher than 39 and $38 \%$ for men and woman, respectively, were accepted for blood donation and enrolled in the study (20). Blood donors with altered liver function and/or with hepatitis $C$ were excluded from the study.

\section{Blood sampling and laboratory determinations}

Peripheral venous blood was drawn using BD Vacutainer System ${ }^{\circledR}$ containing $\mathrm{K}_{3}$ EDTA (Becton Dickinson, USA) for blood cell counts and genetic analysis. An additional blood sample was collected into a BD Vacutainer System ${ }^{\circledR}$ without anticoagulant for measurements of serum iron (SI), serum ferritin (SF), total iron-binding capacity (TIBC), alanine (ALT) and aspartate (AST) aminotransferase activities, and hepatitis $C$ and $B$ immunological markers.

SI, TIBC, ALT, and AST were measured by colorimetric and enzymatic assays using the automated system Advia $1650^{\circledR}$ (Bayer Diagnostics, USA). Transferrin saturation (TS) was estimated as the ratio between SI and TIBC and reported as percentage. SF was determined by an immune assay using the Axsym System ${ }^{\circledR}$ (Abbott Laboratories, USA). Hepatitis $C$ and $B$ were detected by immune assays using the Murex anti-HCV ${ }^{\circledR}$ kit (Murex Biotech S.A., South Africa) and the Hepanostika anti-HBc Uni-Form ${ }^{\circledR}$ and Hepanostika HbsAg Uni-Formll ${ }^{\circledR}$ kits (BioMérieux, The Netherlands), respectively.

\section{Genetic analysis}

Genomic DNA was isolated from whole blood by a salting-out method previously reported (21). HFE C282Y and TFR2 Y250X mutations were detected by the polymerase chain reaction and restriction fragment length polymorphism analysis (PCR-RFLP) as previously described $(22,23)$. The primer sequences (Invitrogen, Brazil) for genotyping the HFE (H63D and S65C) and TFR2 Q690P mutations were modified in the present study using the Primer Premier version 5.0 software (Sigma Chemical Co., USA) based on previously published sequences $(10,13)$. For amplification of the HFE H63D and S65C mutations, we used the following primer sequences: forward 5'-TGTTGCTCTGTCTCCAGGTTCA-3' and reverse 5'-CACAACCACAGCAAGGGTATGT-3', using 34 cycles and a hybridization temperature of $63^{\circ} \mathrm{C}$. The TFR2 Q690P mutation was amplified using the following primer sequences: forward 5'-CTCCAGCACTCTGTCCTCGTCTA-3' and reverse 5'-GCGATCAAAGTGATGAAATGGA-3', using 30 cycles and a hybridization temperature of $60^{\circ} \mathrm{C}$. The PCR assays were carried out using the Eppendorf Mastercycler (Eppendorf, Germany).

PCR products were digested with the Rsal, Mbol, Hinfl, and Bfal endonucleases (New England Biolabs Inc., USA) to detect the HFE C282Y, HFE H63D, HFE S65C, and TFR2 Y250X mutations, respectively. The restriction assay for TFR2 Q690P genotyping was carried out by double digestion with $\mathrm{Bfal}$ and Hpall (New England Biolabs Inc.) to differentiate fragments of similar size after Hpall digestion. Restriction fragments were analyzed by electrophoresis on $2 \%$ agarose gel (HFE C282Y, HFE H63D, HFE S65C, and TFR2 Y250X) and 8\% polyacrylamide gel (TFR2 Q690P). 


\section{Statistical analysis}

Hardy-Weinberg equilibrium was determined for all genotypes using the chi-square test. The distributions of concentrations of SI, TIBC, TS, and SF were all skewed. Logtransformation removed this skew and the variables became normally distributed in order to be used in the parametric tests. Age was skewed because of the difference between groups and was analyzed by the Mann-Whitney test.

The chi-square test or the Fisher exact test was also used to compare the frequencies of donations, genotypes for the HFE C282Y, H63D and S65C mutations, and ethnic groups according to blood donor gender.

One-way analysis of variance (ANOVA), adjusted by age and number of blood donations, was used to compare the mean concentrations of SI, TIBC, TS, and SF from the female and male blood donor groups, formed according to genotypes for three HFE mutations. The same comparisons were performed in groups formed according to the number of blood donations. When ANOVA was significant, the Tukey-Kramer post-test was performed to determine significant differences among groups.

To assess the simultaneous relationship between the various predictors of SF, TS, and TIBC in the male donors at their first blood donation (as dependent variables), three models of multiple linear regression analysis were used. The independent variables were: age, White versus non-White individuals (the non-White group was the reference, and 2 Yellow individuals were excluded from this model), CY versus CC genotype for HFE C282Y mutation (the CC genotype was the reference), $\mathrm{HD}+\mathrm{DD}$ versus $\mathrm{HH}$ genotype for the HFE H63D mutation (the HH genotype was the reference) and $S C$ versus SS genotype for the HFE S65C mutation (the SS genotype was the reference).

All statistical analyses were carried out using statistical analysis software (SAS - Statistical Analysis System for Windows, version 8.02, SAS Institute Inc., USA), with the level of significance set at $P<0.05$.

\section{Results}

\section{General data of the sample population}

Of the 542 eligible subjects, $371(68.5 \%)$ were male donors. The distribution of age, color groups, blood donation frequency groups, frequencies of HFE genotypes and HFE combined genotypes are presented in Table 1.

The frequencies of blood donation differed between genders. The percentage of women $(35.7 \%)$ was significantly higher than the percent- age of men $(20.8 \%, P<0.001)$ in the first-time donor group, while there was a higher percentage of men $(45.0 \%)$ than women $(32.7 \%, \mathrm{P}<0.001)$ in the frequent donor group (Table 1).

\section{Frequencies of the HFE and TFR2 mutations}

The frequencies of the HFE 282Y, HFE 63D and HFE $65 \mathrm{C}$ alleles were $2.1,13.6$, and $0.6 \%$, respectively. No difference was found in the allele frequencies in male and female blood donors according to the skin color $(P>0.05)$. The genotype distributions for HFE mutations were in HardyWeinberg equilibrium (Table 1). The TFR2 250X and TFR2 $690 \mathrm{P}$ alleles were not detected in a subpopulation of donors

Table 1. Demographic and genetic characteristics of the blood donors who participated in the present study.

\begin{tabular}{lcc}
\hline & Women, N (\%) & Men, N (\%) \\
\hline Gender & 171 & 371 \\
Age (years) & & \\
Skin color $^{*}$ & $31.3(29.8-32.9)$ & $32.6(31.6-33.7)$ \\
White & & \\
Intermediate & $91(53.4)$ & $201(54.2)$ \\
Black & $56(32.9)$ & $110(29.7)$ \\
Yellow & $21(12.4)$ & $58(15.6)$ \\
Frequency of blood donations ${ }^{* *}$ & $2(1.3)$ & $2(0.5)$ \\
First time & & \\
Sporadic & $61(35.7)$ & $77(20.8)$ \\
Frequent & $54(31.6)$ & $127(34.2)$ \\
HFE C282Y genotype** & $56(32.7)$ & $167(45.0)$ \\
CC & & \\
CY & $164(95.9)$ & $355(95.7)$ \\
HFE H63D genotype* & $7(4.1)$ & $16(4.3)$ \\
HH & & \\
HD & $130(76.0)$ & $275(74.1)$ \\
DD & $38(22.2)$ & $89(24.0)$ \\
HFE S65C genotype* & $3(1.8)$ & $7(1.9)$ \\
SS & $171(100.0)$ & $365(98.4)$ \\
SC & 0 & $6(1.6)$ \\
HFE combined genotype C282Y/H63D/S65C* & \\
CC/HH/SS & $124(72.5)$ & $256(69.0)$ \\
CC/HD/SS & $37(21.6)$ & $86(23.2)$ \\
CY/HH/SS & $6(3.5)$ & $13(3.5)$ \\
CC/DD/SS & $3(1.8)$ & $7(1.9)$ \\
CC/HH/SC & 0 & $6(1.6)$ \\
CY/HD/SS & $1(0.6)$ & $3(0.8)$ \\
\hline
\end{tabular}

$\mathrm{N}=$ number of subjects. Age = reported as the geometric mean; $95 \% \mathrm{Cl}$ in parentheses. The genotype distribution for HFE gene mutation of female and male blood donors was in Hardy-Weinberg equilibrium. ${ }^{*}$ Fisher exact, ${ }^{* *}$ chisquare, and ${ }^{* * *}$ Mann-Whitney tests were performed. There was a significant difference between frequencies of blood donations according to gender $(P<$ 0.001). Other comparisons were non-significant $(P>0.05)$. 
from this study (212 donors for the TFR2 Y250X mutation and 516 for the TFR2 Q690P mutation).

Relationship between HFE mutations and iron status SI, TIBC, TS, and SF were not associated with the HFE C282Y or H63D genotype in women ( $P$ > 0.05; Table 2). The $65 \mathrm{C}$ allele was not detected in women.

Interestingly, TIBC was lower in men carrying the HFE 282CY genotype when compared with the 282CC genotype carriers $(P=0.003$; Table 2$)$. In addition, higher SI and TS values were found in men carrying at least one HFE 63D allele (HD plus DD genotypes) than in $\mathrm{HH}$ genotype carriers $(\mathrm{P}<0.05)$. No relationship was found between HFE S65C genotype and iron status in men (Table 2).

\section{Relationship between HFE mutations and iron status according to blood donation frequency}

The lack of association between the HFE C282Y and H63D genotypes and the SI, TIBC, TS, and SF data for

Table 2. Iron status according to HFE C282Y, H63D, and S65C mutations in blood donors.

\begin{tabular}{|c|c|c|c|c|}
\hline & Serum iron ( $\mu \mathrm{g} / \mathrm{dL})$ & TIBC $(\mu \mathrm{g} / \mathrm{dL})$ & Transferrin saturation (\%) & Serum ferritin $(\mu \mathrm{g} / \mathrm{L})$ \\
\hline \multicolumn{5}{|l|}{ Women } \\
\hline \multicolumn{5}{|l|}{ HFE C282Y } \\
\hline \multirow[t]{2}{*}{$\mathrm{CC}$} & $75.1(69.6-81.0)$ & $339.4(328.9-350.3)$ & $21.9(22.0-23.8)$ & $28.1(24.0-32.9)$ \\
\hline & $N=164$ & $N=164$ & $N=164$ & $N=155$ \\
\hline \multirow[t]{2}{*}{$\mathrm{CY}$} & $94.3(69.0-128.9)$ & $333.8(264.6-421.1)$ & $28.2(19.3-41.2)$ & $24.8(11.3-54.5)$ \\
\hline & $N=7$ & $N=7$ & $N=7$ & $N=7$ \\
\hline \multicolumn{5}{|l|}{ HFE H63D } \\
\hline \multirow{2}{*}{$\mathrm{HH}$} & $75.5(69.4-82.1)$ & $339.9(327.8-352.3)$ & $22.0(20.0-24.2)$ & $27.3(22.9-32.4)$ \\
\hline & $N=130$ & $N=130$ & $N=130$ & $N=125$ \\
\hline \multirow[t]{2}{*}{$H D+D D$} & $76.9(65.9-89.6)$ & $336.9(216.0-359.0)$ & $22.7(19.4-26.5)$ & $30.5(21.8-42.6)$ \\
\hline & $\mathrm{N}=41$ & $N=41$ & $N=41$ & $N=37$ \\
\hline \multicolumn{5}{|l|}{ Men } \\
\hline \multicolumn{5}{|l|}{ HFE C282Y } \\
\hline \multirow[t]{2}{*}{$\mathrm{CC}$} & $87.8(84.4-91.3)$ & $311.3(305.3-317.3)$ & $28.0(26.8-29.2)$ & $90.4(82.4-99.1)$ \\
\hline & $N=355$ & $N=355$ & $\mathrm{~N}=355$ & $N=328$ \\
\hline \multirow[t]{2}{*}{$\mathrm{CY}$} & $86.2(70.0-106.1)$ & $262.6(207.0-333.3)$ & $31.1(24.1-40.3)$ & $133.0(92.3-191.6)$ \\
\hline & $N=16$ & $N=16$ & $N=16$ & $N=16$ \\
\hline$P$ & & 0.003 & & \\
\hline \multicolumn{5}{|l|}{ HFE H63D } \\
\hline \multirow[t]{2}{*}{$\mathrm{HH}$} & $88.3(81.4-89.3)$ & $307.8(300.1-315.7)$ & $27.4(26.0-28.8)$ & $88.7(80.1-98.3)$ \\
\hline & $N=275$ & $\mathrm{~N}=275$ & $\mathrm{~N}=275$ & $N=256$ \\
\hline \multirow[t]{2}{*}{$H D+D D$} & $95.2(89.2-101.6)$ & $312.4(301.2-324.1)$ & $30.3(28.3-32.4)$ & $102.3(84.9-123.4)$ \\
\hline & $N=96$ & $N=96$ & $N=96$ & $N=88$ \\
\hline$P$ & 0.016 & & 0.048 & \\
\hline \multicolumn{5}{|l|}{ HFE S65C } \\
\hline \multirow[t]{2}{*}{ SS } & $87.6(84.2-91.1)$ & $309.5(303.0-316.1)$ & $28.0(26.8-29.2)$ & $91.7(83.7-100.4)$ \\
\hline & $N=365$ & $N=365$ & $N=365$ & $N=338$ \\
\hline \multirow[t]{2}{*}{ SC } & $97.3(73.3-129.2)$ & $281.6(241.0-328.9)$ & $34.3(25.0-46.9)$ & $111.7(61.2-203.9)$ \\
\hline & $N=6$ & $N=6$ & $N=6$ & $\mathrm{~N}=6$ \\
\hline
\end{tabular}

Data are reported as geometric mean with $95 \% \mathrm{Cl}$ in parentheses. $\mathrm{N}=$ number of subjects; TIBC $=$ total ironbinding capacity. The statistical analyses were performed on the log-transformed variables. ANOVA was adjusted by the number of donations in the last 12 months and blood donor age. The HFE $65 \mathrm{C}$ allele was not detected in female blood donors. 
women was independent of first blood donation $(P>0.05$; Table 3).

First-time male blood donors carrying the HFE 282CY genotype had lower TIBC $(P<0.001)$ and higher TS $(P=$ 0.020 ) values than the $282 \mathrm{CC}$ carriers (Table 3 ). In this group, the HFE 63D allele (DD plus 63HD genotypes) was associated with increased SF concentrations $(P=0.015)$. On the other hand, the HFE S65C mutation did not affect the iron variables in this sample (Table 3 ).

No relationship was found between HFE C282Y, H63D and $\mathrm{S} 65 \mathrm{C}$ mutations and iron variables in sporadic or frequent blood donors, independent of gender (data not shown, $\mathrm{P}>0.05$ ).

\section{Predictors of serum ferritin, transferrin saturation and TIBC}

Multiple linear regression analysis was used to evaluate the association between HFE genotype and other variables on SF (model 1), TS (model 2) and TIBC (model 3) values in first-time male blood donors (Table 4). Age (3.91\%, $\mathrm{P}$ $=0.001)$ and HFE 63HD plus 63DD genotypes $(55.84 \%$, $P=0.021)$ were predictors of increased SF concentra-

Table 3. Iron status according to HFE C282Y, H63D, and S65C mutations in first-time blood donors.

\begin{tabular}{|c|c|c|c|c|}
\hline & Serum iron $(\mu \mathrm{g} / \mathrm{dL})$ & TIBC $(\mu \mathrm{g} / \mathrm{dL})$ & Transferrin saturation (\%) & Serum ferritin $(\mu \mathrm{g} / \mathrm{L})$ \\
\hline \multicolumn{5}{|l|}{ Women } \\
\hline \multicolumn{5}{|l|}{ HFE C282Y } \\
\hline \multirow[t]{2}{*}{ CC } & $79.2(70.0-89.7)$ & $336.3(318.1-355.5)$ & $23.2(20.2-26.7)$ & $33.7(26.6-42.8)$ \\
\hline & $N=58$ & $N=58$ & $N=58$ & $N=56$ \\
\hline \multirow[t]{2}{*}{$\mathrm{CY}$} & 95.2 (49.1-184.5) & 368.6 (189.5-716.9) & $25.7(15.8-41.8)$ & $18.8(2.6-135.4)$ \\
\hline & $N=3$ & $\mathrm{~N}=3$ & $N=3$ & $N=3$ \\
\hline \multicolumn{5}{|l|}{ HFE H63D } \\
\hline \multirow[t]{2}{*}{$\mathrm{HH}$} & $81.6(71.6-93.1)$ & $339.0(317.5-362.0)$ & $23.7(20.2-27.8)$ & $31.8(23.3-43.5)$ \\
\hline & $N=43$ & $N=43$ & $N=43$ & $N=42$ \\
\hline \multirow[t]{2}{*}{$H D+D D$} & $76.1(57.9-99.9)$ & $334.8(300.4-373.2)$ & $22.3(17.0-29.2)$ & $35.1(26.4-46.7)$ \\
\hline & $N=18$ & $N=18$ & $N=18$ & $N=17$ \\
\hline \multicolumn{5}{|l|}{ Men } \\
\hline \multicolumn{5}{|l|}{ HFE C282Y } \\
\hline \multirow[t]{2}{*}{ CC } & 89.7 (81.0-99.2) & $301.1(288.3-314.4)$ & $29.7(26.6-33.1)$ & $122.2(105.6-141.5)$ \\
\hline & $N=72$ & $N=72$ & $N=72$ & $\mathrm{~N}=65$ \\
\hline \multirow[t]{2}{*}{$\mathrm{CY}$} & $109.4(62.7-190.9)$ & $189.6(82.9-434.0)$ & $48.8(36.2-65.8)$ & $138.9(58.8-328.4)$ \\
\hline & $N=5$ & $N=5$ & $N=5$ & $N=5$ \\
\hline$P$ & & $<0.001$ & 0.020 & \\
\hline \multicolumn{5}{|l|}{ HFE H63D } \\
\hline \multirow[t]{2}{*}{$\mathrm{HH}$} & 90.9 (80.4-102.8) & $289.2(268.0-312.0)$ & $30.9(27.1-35.2)$ & $112.1(96.1-130.8)$ \\
\hline & $\mathrm{N}=57$ & $\mathrm{~N}=57$ & $N=57$ & $\mathrm{~N}=53$ \\
\hline \multirow[t]{2}{*}{$H D+D D$} & $90.6(77.0-106.4)$ & $301.0(277.3-326.3)$ & $30.0(25.0-36.1)$ & $166.0(120.8-228.0)$ \\
\hline & $N=20$ & $N=20$ & $N=20$ & $\mathrm{~N}=17$ \\
\hline $\mathrm{P}$ & & & & 0.015 \\
\hline \multicolumn{5}{|l|}{ HFE S65C } \\
\hline \multirow[t]{2}{*}{ SS } & $90.4(81.8-100.0)$ & $291.7(274.5-310.1)$ & $30.6(27.4-34.1)$ & $125.2(108.4-144.6)$ \\
\hline & $\mathrm{N}=75$ & $N=75$ & $N=75$ & $N=68$ \\
\hline \multirow[t]{2}{*}{ SC } & $106.7(5.9-1923.8)$ & 306.5 (265.1-354.3) & $34.5(1.5-777.0)$ & $74.3(22.3-247.0)$ \\
\hline & $N=2$ & $\mathrm{~N}=2$ & $N=2$ & $N=2$ \\
\hline
\end{tabular}

Data are reported as geometric mean with $95 \% \mathrm{Cl}$ in parentheses. $\mathrm{N}=$ number of subjects; TIBC = total iron-binding capacity. The statistical analyses were performed on the log-transformed variables. ANOVA was adjusted by blood donor age. The HFE 65C allele was not detected in female blood donors. 
Table 4. Influence of HFE C282Y, H63D, and S65C mutations and other variables on iron status in first-time male blood donors by multiple linear regression analysis.

\begin{tabular}{llrrr}
\hline Dependent variables & \multicolumn{1}{c}{ Independent variables } & Parameter & Standard error & $P$ \\
\hline Serum ferritin & Intercept & -3.13 & 35.62 & \\
Model 1 $(\mathrm{N}=71)$ & Age & 3.91 & 1.17 & 0.001 \\
& White men & 40.31 & 21.35 & \\
& HFE 282CY genotype & 35.13 & 39.80 & \\
& HFE 63HD plus 63DD genotypes & 55.84 & 23.57 & 0.021 \\
& HFE 65SC genotype & -48.67 & 62.63 & \\
Transferrin saturation & Intercept & & & \\
Model 2 $(\mathrm{N}=77)$ & Age & 28.96 & 6.29 & $<0.001$ \\
& White men & 0.08 & 0.20 & \\
& HFE 282CY genotype & 3.21 & 3.71 & \\
& HFE 63HD plus 63DD genotypes & 17.21 & 7.09 & 0.018 \\
TIBC & HFE 65SC genotype & 1.47 & 3.94 & \\
Model 3 $(\mathrm{N}=77)$ & Intercept & 317.08 & 26.74 & $<0.001$ \\
& Age & -0.48 & 0.85 & \\
& White men & 1.98 & 15.76 & \\
& HFE 282CY genotype & -83.65 & 30.12 & 0.007 \\
& HFE 63HD plus 63DD genotypes & 3.69 & 16.74 & \\
& HFE 65SC genotype & -2.03 & 47.35 & \\
\hline
\end{tabular}

$\mathrm{N}=$ number of subjects; TIBC = total iron-binding capacity. The non-White group consisted of Intermediate and Black men, excluding Yellow individuals $(\mathrm{N}=2)$. Three models of multiple linear regression analysis were done. Model 1 = the independent variables were: age; White versus non-White individuals (non-White group was the reference); HFE 282CY versus CC genotype (CC genotype was the reference); HFE 63HD plus DD versus $\mathrm{HH}$ genotype (HH genotype was the reference); HFE 65SC versus SS genotype (SS genotype was the reference). Models 2 and $3=$ the independent variables were the same as in Model 1.

tions, while the HFE 282CY genotype was associated with increased TS $(17.21 \%, P=0.018)$ and reduced TIBC $(-83.65 \%, P=0.007)$ values.

\section{Discussion}

In the present study, the frequency of the HFE 282Y allele $(2.1 \%, \mathrm{P}>0.05)$ was similar to that reported in studies conducted in healthy Brazilian individuals (1.1 to $1.4 \%)(14-16)$ and in blood donors from Colombia $(1.8 \%)$ (24). However, the frequency of this allele was lower $(\mathrm{P}<$ $0.05)$ than those found in blood donors from Northern Italy (4.7\%) (25) and Northern Europe (5.1 to 8.2\%) $(5,26,27)$. In addition, it is known that the HFE C282Y mutation is rare in non-Caucasians $(5,28)$. The low frequency of the HFE $282 \mathrm{Y}$ allele found in the present study could be explained by the high heterogeneity of the ethnic composition of the Brazilian population, which is the result of five centuries of interethnic crosses of peoples from three continents: the European colonizers mainly represented by the Portuguese, the African slaves, and the autochthonous Amerindians (18). We did not find differences in the frequency of the
$282 \mathrm{Y}$ allele between White and Intermediate plus Black individuals $(P>0.05)$. However, the ethnic classification was based on self-identified skin color categorization, which could be considered a limitation of this study.

The frequency of the HFE 63D allele in the present study $(13.6 \%, P>0.05)$ was similar to that found in studies with blood donors from several regions of Italy (14.4-14.9\%) $(25,29)$, in White individuals from the United States $(15.0 \%)$ (30), and in two studies of healthy Brazilian blood donors (10.8 and $10.9 \%, P>0.05)(14,15)$.

The HFE $65 \mathrm{C}$ allele frequency $(0.6 \%, \mathrm{P}>0.05)$ in this sample was similar to that found in another Brazilian study $(1.0 \%)(15)$ and in blood donors from Northern Italy $(0.74 \%)$ (25) and from the Faroe Islands (1.0\%) (27).

To our knowledge, this is the first investigation of TFR2 mutations in a Brazilian population. These mutations were evaluated in Brazilian individuals because it is estimated that approximately 500,000 Portuguese arrived in the country between 1500 and 1808; Brazil also received approximately 4 million immigrants from other parts of the world (Italy, Spain, and German) (31). However, the TFR2 690P and TFR2 250X alleles (initially found in Portuguese 
and Italian individuals, respectively) were not detected in our sample, suggesting that TFR2 mutations are possibly confined to restricted geographical areas (32).

We were not able to demonstrate the effects of HFE mutations on iron status in women. It is possible that the high volume of blood loss during menstrual cycles or the high prevalence of nutritional deficiencies in Brazilian women could be responsible $(33,34)$. In fact, in a previous study, we found high frequencies of iron deficiency $(11.9 \%)$ and iron-deficiency anemia $(6.8 \%)$ in the same female blood donors (35).

Interestingly, men presented some alterations in iron parameters. It is important to emphasize that the alterations found in this study do not reflect the presence of iron overload in blood donors carrying the HFE 282Y or HFE $63 \mathrm{D}$ alleles. However, they were related to slightly increased TS and reduced TIBC concentrations in HFE 282Y allele carriers and elevated SF concentrations in HFE 63D allele carriers in males who donated blood for the first time.

Multiple linear regression analysis confirmed the influence of the HFE 282CY genotype on the TS (directly) and on the TIBC (inversely) values in male first-time blood donors. The hypothesis accepted to explain this finding is that the variant protein (with the presence of the C282Y mutation) abolishes a disulfide bridge in the HFE protein that prevents its interaction with $\beta_{2}$-microglobulin and TFR1, which is free to bind transferrin. Consequently, the iron absorption in enterocytes may be inadequately modulated (4).

It is possible that the effects of these mutations could be improved by interaction with other gene mutations or could possibly have an interaction with some environmental factors, leading to iron overload in the carriers in the next

\section{References}

1. Swinkels DW, Janssen MC, Bergmans J, Marx JJ. Hereditary hemochromatosis: genetic complexity and new diagnostic approaches. Clin Chem 2006; 52: 950-968.

2. Feder JN, Penny DM, Irrinki A, Lee VK, Lebron JA, Watson $\mathrm{N}$, et al. The hemochromatosis gene product complexes with the transferrin receptor and lowers its affinity for ligand binding. Proc Natl Acad Sci U S A 1998; 95: 1472-1477.

3. Fleming RE, Ahmann JR, Migas MC, Waheed A, Koeffler $\mathrm{HP}$, Kawabata $\mathrm{H}$, et al. Targeted mutagenesis of the murine transferrin receptor-2 gene produces hemochromatosis. Proc Natl Acad Sci U S A 2002; 99: 10653-10658.

4. Camaschella C, Roetto A, De Gobbi M. Genetic haemochromatosis: genes and mutations associated with iron loading. Best Pract Res Clin Haematol 2002; 15: 261-276.

5. Merryweather-Clarke AT, Pointon JJ, Shearman JD, Robson KJ. Global prevalence of putative haemochromatosis mutations. J Med Genet 1997; 34: 275-278.

6. Brissot P, Moirand R, Jouanolle AM, Guyader D, Le Gall JY, Deugnier Y, et al. A genotypic study of 217 unrelated probands diagnosed as "genetic hemochromatosis" on two or three decades of life.

Iron parameters are influenced by age, gender, and disease, as well as by biological variation within an individual (36). In the present study, we also considered the frequency of blood donations as a covariate in the statistical analyses of iron parameters (37). HFE mutations influenced iron status markers, such as TIBC and TS, in first-time blood donors but these relationships were not found in sporadic or frequent blood donors. Therefore, the frequency of blood donations seems to be an important variable to be considered in gene-related studies of iron status.

The HFE 282Y and 65C alleles were rare in Brazilian blood donors, while the HFE 63D allele was frequent. TFR2 mutations were not found in this study. HFE C282Y and H63D mutations were associated with alterations in iron status only in male blood donors. Additional prospective studies are required to determine the effects of environmental factors and their possible interactions with HFE C282Y and HFE H63D mutations on the iron status of healthy individuals.

\section{Acknowledgments}

We acknowledge the technical assistance of Fernanda R. Lopreato and Daniella J. Itinoseki. We also thank the blood donors who participated in the study and the health care professional group of Hemocentro da Santa Casa de São Paulo, Brazil. Research supported by CNPq (\#476703/2004-2). C.T. Terada and I. Gonzales were recipients of fellowships from PIBIC-CNPq. P.C.J.L. Santos, R.D.C. Hirata, M.H. Hirata, and E.M. Guerra-Shinohara are recipients of fellowships from CNPq. "classical" phenotypic criteria. J Hepatol 1999; 30: 588593.

7. Carella M, D'Ambrosio L, Totaro A, Grifa A, Valentino MA, Piperno A, et al. Mutation analysis of the HLA-H gene in Italian hemochromatosis patients. Am J Hum Genet 1997; 60: 828-832.

8. Papanikolaou G, Samuels ME, Ludwig EH, MacDonald ML, Franchini PL, Dube MP, et al. Mutations in HFE2 cause iron overload in chromosome 1q-linked juvenile hemochromatosis. Nat Genet 2004; 36: 77-82.

9. Feder JN, Gnirke A, Thomas W, Tsuchihashi Z, Ruddy DA, Basava A, et al. A novel MHC class I-like gene is mutated in patients with hereditary haemochromatosis. Nat Genet 1996; 13: 399-408.

10. Mura $C$, Raguenes $\mathrm{O}$, Ferec $\mathrm{C}$. HFE mutations analysis in 711 hemochromatosis probands: evidence for S65C implication in mild form of hemochromatosis. Blood 1999; 93: 2502-2505.

11. Beutler $E$. The significance of the $187 \mathrm{G}(\mathrm{H} 63 \mathrm{D})$ mutation in hemochromatosis. Am J Hum Genet 1997; 61: 762-764. 
12. Camaschella C, Roetto A, Cali A, De Gobbi M, Garozzo G, Carella M, et al. The gene TFR2 is mutated in a new type of haemochromatosis mapping to 7q22. Nat Genet 2000; 25: 14-15.

13. Mattman A, Huntsman D, Lockitch G, Langlois S, Buskard N, Ralston D, et al. Transferrin receptor 2 (TfR2) and HFE mutational analysis in non-C282Y iron overload: identification of a novel TfR2 mutation. Blood 2002; 100: 1075-1077.

14. Agostinho MF, Arruda VR, Basseres DS, Bordin S, Soares MC, Menezes RC, et al. Mutation analysis of the HFE gene in Brazilian populations. Blood Cells Mol Dis 1999; 25: 324327.

15. Bueno S, Duch CR, Figueiredo MS. Mutations in the HFE gene (C282Y, H63D, S65C) in a Brazilian population. Rev Bras Hematol Hemoter 2006; 28: 293-295.

16. Torres FR, Souza-Neiras WC, D'Almeida Couto AA, D'Almeida Couto VS, Cavasini CE, Rossit AR, et al. Frequency of the HFE C282Y and H63D polymorphisms in Brazilian malaria patients and blood donors from the Amazon region. Genet Mol Res 2008; 7: 60-64.

17. http://www.ibge.gov.br/home/estatistica/populacao/censo2000/. Accessed September 8, 2009.

18. Parra FC, Amado RC, Lambertucci JR, Rocha J, Antunes CM, Pena SD. Color and genomic ancestry in Brazilians. Proc Natl Acad Sci U S A 2003; 100: 177-182.

19. Vargens DD, Almendra L, Struchiner CJ, Suarez-Kurtz G. Distribution of the GNB3 825C>T polymorphism among Brazilians: impact of population structure. Eur J Clin Pharmacol 2008; 64: 253-256.

20. Agência Nacional de Vigilância Sanitária do Brasil. RDC 153, de 14 de junho de 2004. <http://www.anvisa.gov.br/ sangue/legis/>. Accessed September 8, 2009.

21. Salazar LA, Hirata MH, Cavalli SA, Machado MO, Hirata RD. Optimized procedure for DNA isolation from fresh and cryopreserved clotted human blood useful in clinical molecular testing. Clin Chem 1998; 44: 1748-1750.

22. Best LG, Harris PE, Spriggs EL. Hemochromatosis mutations C282Y and H63D in 'cis' phase. Clin Genet 2001; 60: 68-72.

23. Roetto A, Totaro A, Piperno A, Piga A, Longo F, Garozzo G, et al. New mutations inactivating transferrin receptor 2 in hemochromatosis type 3. Blood 2001; 97: 2555-2560.

24. Avila-Gomez IC, Aristizabal-Bernal B, Jimenez-Del-Rio M, Velez-Pardo C. Prevalence of H63D, S65C and C282Y mutations of the HFE gene in 1120 voluntary blood donors from Antioquia region of northwest Colombia. Blood Cells Mol Dis 2008; 40: 449-451.
25. Salvioni A, Mariani R, Oberkanins C, Moritz A, Mauri V, Pelucchi S, et al. Prevalence of C282Y and E168X HFE mutations in an Italian population of Northern European ancestry. Haematologica 2003; 88: 250-255.

26. Simonsen K, Dissing J, Rudbeck L, Schwartz M. Rapid and simple determination of hereditary haemochromatosis mutations by multiplex PCR-SSCP: detection of a new polymorphic mutation. Ann Hum Genet 1999; 63: 193-197.

27. Milman N, Steig $T$, Koefoed $P$, Pedersen $P$, Fenger $K$, Nielsen FC. Frequency of the hemochromatosis HFE mutations C282Y, H63D, and S65C in blood donors in the Faroe Islands. Ann Hematol 2005; 84: 146-149.

28. Mercier G, Bathelier C, Lucotte G. Frequency of the C282Y mutation of hemochromatosis in five French populations. Blood Cells Mol Dis 1998; 24: 165-166.

29. Pozzato G, Zorat F, Nascimben F, Gregorutti M, Comar C, Baracetti S, et al. Haemochromatosis gene mutations in a clustered Italian population: evidence of high prevalence in people of Celtic ancestry. Eur J Hum Genet 2001; 9: 445451.

30. McLaren CE, Li KT, Garner CP, Beutler E, Gordeuk VR. Mixture distribution analysis of phenotypic markers reflecting HFE gene mutations. Blood 2003; 102: 4563-4566.

31. Pimenta JR, Zuccherato LW, Debes AA, Maselli L, Soares RP, Moura-Neto RS, et al. Color and genomic ancestry in Brazilians: a study with forensic microsatellites. Hum Hered 2006; 62: 190-195.

32. De Gobbi M, Barilaro MR, Garozzo G, Sbaiz L, Alberti F, Camaschella C. TFR2 Y250X mutation in Italy. Br J Haematol 2001; 114: 243-244.

33. Niederau C, Fischer R, Purschel A, Stremmel W, Haussinger D, Strohmeyer G. Long-term survival in patients with hereditary hemochromatosis. Gastroenterology 1996; 110: 1107-1119.

34. Barton JC, McDonnell SM, Adams PC, Brissot P, Powell $L W$, Edwards $C Q$, et al. Management of hemochromatosis. Hemochromatosis Management Working Group. Ann Intern Med 1998; 129: 932-939.

35. Terada CT, Santos PC, Cancado RD, Rostelato S, Lopreato FR, Chiattone CS, et al. Iron deficiency and frequency of HFE C282Y gene mutation in Brazilian blood donors. Transfus Med 2009; 19: 245-251.

36. Worwood M. Genetics of haemochromatosis. Baillieres Clin Haematol 1994; 7: 903-918.

37. Milman N, Sondergaard M. Iron stores in male blood donors evaluated by serum ferritin. Transfusion 1984; 24: 464468. 